\title{
Glycogen synthase kinase-3: a promising therapeutic target for fragile $\mathrm{X}$ syndrome
}

\section{Marjelo A. Mines and Richard S. Jope*}

Department of Psychiatry and Behavioral Neurobiology, University of Alabama at Birmingham, Birmingham, AL, USA

\section{Edited by:}

Oksana Kaidanovich-Beilin, Samuel

Lunenfeld Research Institute, Canada

\section{Reviewed by:}

Peter C. Kind, University of

Edinburgh, UK

Randi Hagerman, UC Davis Medical

Center, USA

\section{*Correspondence:}

Richard S. Jope, Department of Psychiatry, University of Alabama at Birmingham, 1720 Seventh Avenue South, SC1057, Birmingham, AL 35294-0017, USA.

e-mail:jope@uab.edu
Recent advances in understanding the pathophysiological mechanisms contributing to fragile $X$ syndrome (FXS) have increased optimism that drug interventions can provide significant therapeutic benefits. FXS results from inadequate expression of functional fragile $\mathrm{X}$ mental retardation protein (FMRP). FMRP may have several functions, but it is most well-established as an RNA binding protein that regulates translation, and it is thought that by this mechanism FMRP is capable of affecting numerous cellular processes by selectively regulating protein levels. The multiple cellular functions regulated by FMRP suggest that multiple interventions may be required for reversing the effects of deficient FMRP. Evidence that inhibitors of glycogen synthase kinase-3 (GSK3) may contribute to the therapeutic treatment of FXS is reviewed here. Lithium, a GSK3 inhibitor, improved function in the Drosophila model of FXS. In mice lacking FMRP expression (FX mice), GSK3 is hyperactive in several brain regions. Significant improvements in several FX-related phenotypes have been obtained in FX mice following the administration of lithium, and in some case other GSK3 inhibitors. These responses include normalization of heightened audiogenic seizure susceptibility and of hyperactive locomotor behavior, enhancement of passive avoidance learning retention and of sociability behaviors, and corrections of macroorchidism, neuronal spine density, and neural plasticity measured electrophysiologically as long term depression. A pilot clinical trial of lithium in patients with FXS also found improvements in several measures of behavior. Taken together, these findings indicate that lithium and other inhibitors of GSK3 are promising candidate therapeutic agents for treating FXS.

Keywords: glycogen synthase kinase-3, GSK3, fragile X syndrome, FXS, autism

\section{INTRODUCTION}

During the last few years there has been tremendous progress in understanding the pathological mechanisms underlying fragile $\mathrm{X}$ syndrome (FXS). This knowledge has provided several leads of potential interventions that may be therapeutic in FXS. One of these is lithium and possibly other inhibitors of glycogen synthase kinase-3 (GSK3), and this evidence is discussed in this review.

\section{FRAGILE X SYNDROME: ETIOLOGY AND PATHOLOGY}

Fragile X syndrome is the most common hereditary form of mental retardation caused by a single genetic defect, the loss of expression of the fragile X mental retardation 1 ( $f m r 1$ ) gene (Pieretti et al., 1991; Kooy et al., 2000; Bardoni and Mandel, 2002). FXS is caused by expansion of a trinucleotide CGG repeat in the $5^{\prime}$ UTR of the fmrl gene. This expansion appears as a weak, or fragile-like, end on the X chromosome. Normally there are $\sim 5$ to $\sim 44$ CGG repeats containing occasional AGG triplets, with 29 or 30 being most common (Maddalena et al., 2001). Alleles in the range of 45-54 repeats are considered to be in a gray, or inconclusive, zone; premutation alleles range from 55 to 200-230 CGG repeats, which may reduce translation efficiency of the FMR1 gene (Feng et al., 1995); and full mutations associated with FXS have over 200-230 CGG repeats, typically containing several hundred or thousand triplet repeats (Maddalena et al., 2001). The extended CGG repeats in FXS are hypermethylated, silencing gene transcription and resulting in loss of the fragile $\mathrm{x}$ mental retardation protein (FMRP). FMRP plays important roles in RNA binding and translation regulation, as well as regulation of extracellular transport and sodium-activated potassium channels (Brown et al., 1998, 2010; Bardoni et al., 2000; Laggerbauer et al., 2001).

Since FXS is an X-linked developmental disorder, its incidence is higher in males than females, affecting $\sim 1$ in 4000 males and $\sim 1$ in 7000 females (Crawford et al., 2001). Transmission of the affected fmrl allele may occur to female offspring from an affected male and to both male and female offspring from affected females. FXS is characterized by several physical, mental, and behavioral abnormalities. Prominent physical characteristics include overly pronounced ears, an elongated jaw, double-jointed/hyperextensible fingers, flat feet, low muscle tone, and macroorchidism. Sleep disturbances, inattentiveness, hyperactivity, impaired cognition, seizure susceptibility, and autistic-like behaviors, including developmental delays, communication impairments, and anxiety, are common characteristics of patients with FXS.

\section{ANIMAL MODELS OF FXS}

The most common animal models used to study FXS include mouse models (Bakker et al., 1994) and Drosophila models (Wan et al., 2000; Zhang et al., 2001). The first mouse model was developed by Bakker et al. (1994), who generated mice with an inactive Fmrl gene (FX mice). With these and other FMRP knockout 
mice, FX mice have been shown to display characteristics with some similarities to patients with FXS, including macroorchidism, certain features of behavior, and some cognitive impairments. However, the impairments in measures of cognition that have been assessed in FX mice are modest compared to patients with FXS, although a recent report identified a significant impairment in prefrontal cortex-dependent cognition in FX mice (Krueger et al., 2011). FX mice also exhibit increased dendritic spine length and number, but reduced maturation of spines, compared to wildtype littermates (Comery et al., 1997; Irwin et al., 2001, 2002). Autistic-like behaviors characteristic of patients with FXS, and increased susceptibility to audiogenic seizures also occur in FX mice (Musumeci et al., 2000; Yan et al., 2004; Bernerdet and Crusio (2006). The use of Drosophila to study FXS was initiated by Wan et al. (2000), who identified $d f m r 1$ as the invertebrate family member of the FMR1/FXR gene family. Over-expression of RNA binding-deficient mutant $d f m r 1$ in Drosophila caused wing deformities, including loss of anterior cross-veins longitudinal veins, and severe rough eye, suggesting altered cell fate determination and proliferation, and increased apoptosis. Drosophila FXS models lacking expression of dFMRP or over-expressing a loss-offunction dFMRP mutant were characterized by Zhang et al. (2001). Over-expression of loss-of-function mutant dFMRP produced an abnormal wing span or up-held wings, impaired coordination, caused early death, and dFMRP-null flies displayed exaggerated synaptic outgrowth (Zhang et al., 2001). Knockout and mutation of $d f m r 1$ also affected neurotransmission and increased peripheral synaptic transmission while decreasing central synaptic transmission. Thus, both the mouse and fly models of FXS have provided valuable information about the pathology of FXS and contributed to recent advances in developing potential therapeutic interventions for FXS.

\section{GLYCOGEN SYNTHASE KINASE-3}

Glycogen synthase kinase-3 is a serine/threonine kinase that exists in two isoforms, GSK3 $\alpha$ and GSK3 $\beta$ (Woodgett, 1990). Regulation of GSK3 is primarily mediated by inhibitory serinephosphorylation, specifically at ser 21 of GSK3 $\alpha$ and ser9 of GSK3 $\beta$. The inhibitory serine-phosphorylation of GSK3 is induced by a wide variety of signaling pathways that converge on GSK3. Impairments in these pathways can lead to inadequate inhibition of GSK3, causing hyperactive GSK3, which may contribute to a number of diseases, such as Alzheimer's disease, diabetes, and mood disorders (Jope and Johnson, 2004; Mines et al., 2011). Studies of the actions of GSK3 were accelerated by the discovery that lithium, the classical treatment for bipolar disorder, is a selective inhibitor of GSK3 (Klein and Melton, 1996; Stambolic et al., 1996). Lithium both directly inhibits GSK3 activity and also increases the inhibitory serine-phosphorylation of GSK3 (Jope, 2003). Studies of the effects of lithium contributed immensely to the identification of many of the known actions of GSK3 and to revelations that inadequately inhibited GSK3 is linked to a number of diseases, which includes FXS, as is reviewed here. Connecting GSK3 to pathological processes promoted the development of many new, small molecule selective inhibitors of GSK3 (Martinez et al., 2006). Some GSK3 inhibitors that have been used fairly extensively in experimental studies include indirubin derivatives
(Leclerc et al., 2001), L803-mts (Plotkin et al., 2003), SB216763 (Coghlan et al., 2000), TDZD derivatives (Martinez et al., 2002), paullone derivatives (Leost et al., 2000), AR-A014418 (Bhat et al., 2003), and CT99021 (Wagman et al., 2004), the most specific GSK3 inhibitor that has been described (Bain et al., 2007). Of these, only a TDZD derivative called tideglusib is currently in trials in humans (Martinez et al., 2011), and none has yet been tested in patients with FXS.

\section{AMELIORATION OF FXS-ASSOCIATED BEHAVIORAL ABNORMALITIES BY LITHIUM AND OTHER GSK3 INHIBITORS}

McBride et al. (2005) reported that lithium treatment ameliorated impairments in courtship behavior in the Drosophila model of FXS. This was a critical finding because it first raised the possibility that lithium may be therapeutic for FXS. A subsequent report confirmed the rescue of FXS-associated impairments in the Drosophila model of FXS by lithium treatment and demonstrated that this rescue was sustainable throughout the aging process (Choi et al., 2009). Since lithium both inhibits GSK3 and modulates phosphoinositide signaling (Jope, 1999), the key target for its effects in the Drosophila model of FXS has yet to be established.

Direct evidence that GSK3 may be involved in the pathology of FXS and be a target for the development of treatments for FXS was obtained in studies of the regulation of GSK3 in brain regions from FX mice. Assessments of the levels of serinephosphorylation of GSK3 revealed that adult FX mice had lower levels of inhibitory phospho-ser21-GSK3 $\alpha$ and phospho-ser9GSK3 $\beta$ in several brain regions compared to wild-type littermates (Min et al., 2009; Yuskaitis et al., 2010a). However the total protein levels of GSK3 $\alpha$ and GSK3 $\beta$ were equivalent in FX and wild-type mice, demonstrating that GSK3 expression is normal in FX mouse brain, but the inhibitory control of GSK3 is impaired. The impairment in the regulation of GSK3 was evident in adult FX mice on both the FVB and C57Bl6 backgrounds, thus this is a robust change not dependent on mouse strain, and reduced inhibitory serine-phosphorylation of GSK3 in FX mice was also found in an analysis of whole brain GSK3 phosphorylation levels (Liu et al., 2011). Moreover, impaired inhibitory serine-phosphorylation of GSK3 in adult FX mice was corrected by acute or chronic treatment with lithium (Min et al., 2009; Yuskaitis et al., 2010a; Liu et al., 2011).

The effects of lithium, and in some cases other GSK3 inhibitors, have been tested on several behavioral characteristics of FX mice. Increased susceptibility to audiogenic seizures, which often evolve to lethal status epilepticus, is a well-established phenotype of FX mice (Musumeci et al., 2000). Treatment with lithium dosedependently reduced audiogenic seizure susceptibility in 4-weekold FX mice, but did not alter the responses in wild-type mice (Min et al., 2009). The occurrence of status epilepticus was also dosedependently reduced by lithium in FX mice (Min et al., 2009). To assess whether decreased audiogenic seizure susceptibility was a result of lithium-mediated inhibition of GSK3, the effects of two additional GSK3 inhibitors were investigated. Treatment with the selective GSK3 inhibitors AR-A014418 (Bhat et al., 2003) or SB216763 (Coghlan et al., 2000) normalized audiogenic seizure susceptibility in FX mice similarly to the effect of lithium treatment. The finding that three structurally diverse GSK3 inhibitors 
were able to reduce audiogenic seizure susceptibility in FX mice, without affecting audiogenic seizure susceptibility in wild-type mice, suggested that the hyperactive GSK3 identified in FX mouse brain is likely mediating the phenotypic seizure abnormalities in FX mice (Min et al., 2009).

Locomotor hyperactivity is a hallmark characteristic of FXS that is also evident in FX mice (Bakker et al., 1994). Therefore, the effects of lithium were examined in FX mice to test if locomotor hyperactivity was ameliorated. Untreated FX mice displayed increased hyperactivity in the open field paradigm (Min et al., 2009; Yuskaitis et al., 2010a; Liu et al., 2011), including significant increases in total line crosses, in center square duration, and in center square entries, and a significant decrease in outer zone line crosses compared with wild-type mice (Min et al., 2009). Administration of SB216763 to inhibit GSK3 did not alter the activity of wild-type mice in the open field, but normalized the total line crosses, center square entries, center square duration, and outer zone line crosses in FX mice (Min et al., 2009). Chronic lithium administration at a therapeutically relevant dose also normalized to wild-type levels the total ambulatory distance traveled by FX mice in the open field, without altering the distance traveled by wild-type mice (Yuskaitis et al., 2010a; Liu et al., 2011). The correction of locomotor hyperactivity of FX mice by two GSK3 inhibitors suggests that hyperactive GSK3 in FX mice makes a significant contribution to this phenotype.

The effect of lithium treatment on the behavior of adult FX and wild-type mice on the elevated plus maze paradigm also has been assessed. This behavioral paradigm uses a cross shaped apparatus consisting of two open arms and two closed arms. Typically, this apparatus is often used to estimate anxiety displayed by hesitation to explore the open arms resulting in increased time spent in the closed arms, although interpretations of the results remain complicated, especially with mice that exhibit locomotor hyperactivity. FX mice spent significantly more time in the open arms and less time in the closed arms than wild-type mice, which would classically be interpreted as exhibition of less anxiety (Yuskaitis et al., 2010a; Liu et al., 2011), but FX mice also displayed an increase in closed arm entries, classically interpreted as increased anxiety (Yuskaitis et al., 2010a). Thus, the locomotor hyperactivity of FX mice may preclude clear interpretations of the measurements using the elevated plus maze paradigm. Despite the difficulty in interpreting the behaviors, administration of lithium normalized behavior in the elevated plus maze paradigm in FX mice to the behavior of wild-type mice (Yuskaitis et al., 2010a; Liu et al., 2011). The elevated zero maze was also used to assess anxiety-like behaviors in FX mice (Liu et al., 2011). The elevated zero maze has two closed quadrants and two open quadrants, and the time spent in the open or closed portions is indicative of the presence or absence of anxiety or fearfulness versus exploratory behaviors. FX mice spent more time in the open quadrants than wild-type mice, and lithium treatment reduced the time spent in the open quadrants, eliminating the difference between FX mice and wild-type mice (Liu et al., 2011). Thus, FX mice display abnormal behavior in each of these tests that is normalized by lithium, but relating these behaviors to the behavior of subjects with FXS remains difficult.

Another common characteristic of patients with FXS is the presence of autistic-like behaviors (Hagerman et al., 2005;
Belmonte and Bourgeron, 2006; Hatton et al., 2006). FXS is the most common known genetic cause of autism spectrum disorders (ASDs), which can involve developmental delays, communication impairments, anxiety, and impaired social behaviors. Accordingly, social behavior deficits have been extensively described in FX mice (Mineur et al., 2002, 2006; Spencer et al., 2005; Bernerdet and Crusio, 2006; McNaughton et al., 2008; Liu and Smith, 2009; Moy et al., 2009). The effects of lithium treatment on social behavior were studied using the two-phase social interaction behavior paradigm (McNaughton et al., 2008). This test consists of a sociability phase 1 , the introduction of one novel stimulus mouse (S1), and a social preference phase 2, the introduction of a second stimulus mouse (S2). Although during the sociability phase FX mice generally behaved as wild-type mice, lithium treatment increased sociability measures in both wild-type and FX mice (Mines et al., 2010; Liu et al., 2011), increasing the time in the socializing chamber (Mines et al., 2010; Liu et al., 2011) and increasing social approach assessed by the number of nose contacts (Mines et al., 2010) and by the time spent sniffing the stimulus mouse (Liu et al., 2011). In the social preference phase 2, wild-type mice display preference for S2 over S1, but FX mice lacked this preference and spent equivalent times with S1 and S2 (Mines et al., 2010; Liu et al., 2011) and displayed a lower number of nose contacts with S2 and time sniffing S2 than wild-type mice (Mines et al., 2010; Liu et al., 2011). These abnormal behaviors in the social preference assessment of FX mice were significantly normalized by chronic lithium treatment (Mines et al., 2010; Liu et al., 2011). Lithium treatment also appeared to modestly reduce displays of social anxiety by FX mice (Mines et al., 2010). To test if hyperactive GSK3 might contribute to the altered social behaviors exhibited by FX mice, in addition to administering lithium to inhibit GSK3, another model of hyperactive GSK3 was used, GSK3 knockin mice. These mice have serine-to-alanine mutations in the regulatory serines of GSK3 $\alpha$ and GSK3 $\beta$, so the mice express constitutively active GSK3 that cannot be inhibited by serine-phosphorylation (McManus et al., 2005). These mice also displayed no altered behavior in the sociability phase 1 test, but displayed impairments in the social preference phase 2 similar to those of FX mice (Mines et al., 2010). Collectively, these studies suggest that GSK3 inhibition may be useful in reducing impairments in social behaviors and social anxiety in FXS.

\section{GSK3 AND MORPHOLOGY IN FX MICE}

In addition to improving abnormal behaviors in FX models, lithium treatment also modified structural and anatomical characteristics of FX mice. Macroorchidism is a common feature of FXS that is replicated in FX mice (Bakker et al., 1994; Comery et al., 1997). Chronic administration of lithium significantly reduced testicular weight in adult FX mice, but not in adult wild-type mice (Yuskaitis et al., 2010b). Increased dendritic spine length with altered morphology are characteristic of FXS and replicated in FX mice (Comery et al., 1997). Liu et al. (2011) confirmed increased apical and basal dendritic spine length in FX mice as compared to wild-type littermates. Furthermore, they found that lithium treatment normalized dendritic spines in FX mice (Liu et al., 2011). Reactive astrogliosis has been reported in postmortem brains of patients with ASDs (Laurence and Fatemi, 2005; Vargas et al., 2005). Yuskaitis et al. (2010b) reported that adult FX mice 
displayed increased levels of glial fibrillary acidic protein (GFAP), a classical marker of astrogliosis, in several brain regions, including the striatum, hippocampus, and cortex, and that chronic lithium treatment reduced GFAP levels in both adult FX and wild-type mice. Although the mechanism for this effect of lithium was not examined, the transcription factor signal transducer and activator of transcription-3 (STAT3) promotes GFAP expression and is inhibited by inhibitors of GSK3, including lithium (Beurel and Jope, 2008), raising the possibility that this action accounted for the reduced levels of GFAP in vivo after lithium treatment.

\section{GSK3, mGLURs, AND SYNAPTIC PLASTICITY}

Alterations in synaptic plasticity have been a focus of studies of FXS since early reports found that FMRP may be important for normal maturation of synaptic connections (Weiler et al., 1997; Weiler and Greenough, 1999; Antar et al., 2004) and FX mice displayed enhanced metabotropic glutamate receptor (mGluR)-dependent long term depression (LTD) in the CA1 region of the hippocampus (Huber et al., 2002). These and other reports (e.g., McBride et al., 2005; Yan et al., 2005; Dölen et al., 2007) have strengthened the mGluR theory of FXS (Bear et al., 2004), which proposes that many of the protein synthesis-dependent functions of metabotropic receptors are exaggerated in FXS. This has led to the development of mGluR5 antagonists as potential therapeutics for FXS. The mGluR5 antagonist MPEP (2-methyl-6-phenylethynyl-pyridine) has often been used in studies of FX mice, and MPEP treatment rescues a number of impairments, such as heightened audiogenic seizure susceptibility (Yan et al., 2005). Surprisingly, administration of MPEP also increased the inhibitory serine-phosphorylation of GSK3 in FX mouse brain, while having little effect in wild-type mice (Min et al., 2009; Yuskaitis et al., 2010a). This finding indicated that mGluR5 signaling to GSK3 is abnormal in FX mice, and demonstrated an overlap in the effect of MPEP with GSK3 inhibitors. Furthermore, Choi et al. (2011) found that lithium treatment ameliorated enhanced mGluR-mediated LTD at CA1 synapses in FX mice. Although the mechanism underlying this action of lithium was not examined, that it might be due to inhibition of GSK3 is consistent with the finding that GSK3 promotes LTD (Peineau et al., 2007). Taken together, these studies lend further support to the possibility that inhibition of GSK3 may be a beneficial therapeutic intervention for FXS.

\section{CLINICAL TRIALS}

The promising reports that lithium corrects FX-associated abnormalities in flies and mice was corroborated in a pilot clinical trial of lithium in patients with FXS (Berry-Kravis et al., 2008). The use of lithium in humans is well-established because it has been used clinically for 60 years in the treatment of mood disorders, especially bipolar disorder (Jope, 1999). Berry-Kravis et al. (2008) assessed the clinical effects of lithium in patients with FXS given lithium carbonate orally with doses adjusted to obtain a serum level of $0.8-1.2 \mathrm{mEq} / \mathrm{L}$ for the final 4 weeks of a 2 -month trial. This pilot trial found that aggression, anxiety, mood swings, tantrums, and abnormal outbursts were improved in lithium-treated patients. Care-giver ratings indicated decreases in hyperactivity and inappropriate speech. Improvements in lethargy and stereotypy were also observed in patients given lithium, as compared to baseline behaviors previously recorded (Berry-Kravis et al., 2008). Overall, these findings further bolster the possibility that lithium, and perhaps other GSK3 inhibition, may provide therapeutic benefits in FXS.

\section{POTENTIAL TARGETS OF GSK3 THAT MAY CONTRIBUTE TO FXS ABNORMALITIES}

Since GSK3 was only recently found to be hyperactive in FX mouse brain and to be a potential therapeutic target for FXS, identification of the mechanisms by which GSK3 may contribute to FXS phenotypes awaits future investigations. However, several possibilities can be suggested representative of the cellular functions regulated by GSK3 and the abnormalities that have been identified in FX mice.

Regulation of cellular cytoskeleton dynamics provides one potential mechanism by which hyperactive GSK3 could contribute to abnormalities in FXS brain. Prevalent among GSK3 substrates are microtubule-associated proteins (MAPs) that regulate dynamic changes in neuronal plasticity, which is thought to be abnormal in FXS. Microtubules are polymers of the protein tubulin composing networks that maintain the structure and spatial organization of cells and that provide mechanisms for transporting organelles and protein complexes within cells. Microtubules are dynamic structures capable of rapid changes mediated by increased tubulin polymerization or, oppositely, by microtubule depolymerization. These changes occur in response to signals that regulate MAPs, which reversibly bind microtubules and regulate microtubule stability, allowing cells to change shape, extend or retract processes, and to move. Among the MAP family, the protein tau is the most widely studied substrate of GSK3 (Hong et al., 1997; Cho and Johnson, 2004), primarily because of its links to Alzheimer's disease (Johnson and Bailey, 2002). There are many phosphorylation sites on tau, and in general tau phosphorylation reduces its binding to microtubules, whereas dephosphorylated tau tends to bind and stabilize microtubules. Tau binding stabilizes microtubules, and phosphorylation by GSK3 causes tau to dissociate from microtubules, which destabilizes microtubules. Thus, hyperactive GSK3 in FX brains may reduce tau binding to microtubules. Also, a dramatic $\sim 50 \%$ loss of tau protein has been reported in FX cortical neurons (Liao et al., 2008), which could result from its degradation following phosphorylation by GSK3. Considering together the possibilities of tau hyperphosphorylation by GSK3, which dissociates tau from microtubules, and the lower level of tau available to bind and stabilize microtubules, these alterations could contribute to deficits in structural plasticity that may contribute to impaired neuronal plasticity in FXS. Additionally, cyclin-dependent kinase-5 (Cdk5) levels are low in FX cortical neurons (Liao et al., 2008) and normally Cdk5 suppresses GSK3 activity through neuregulin and Akt signaling to reduce tau phosphorylation (Wen et al., 2008). Thus, the reduced Cdk5 levels in FX brain may contribute to hyperactive GSK3 and abnormal phosphorylation of tau. Similarly to tau, GSK3 also phosphorylates and regulates the function of other proteins that bind and regulate microtubules, including MAP1B (Garcia-Perez et al., 1998; Lucas et al., 1998). Notably, MAP1B was one of the earliest targets found to be regulated by FMRP, and aberrantly regulated MAP1B leads to abnormally increased microtubule stability in FX neurons 
(Zhang et al., 2001; Lu et al., 2004). Thus, abnormal phosphorylation by GSK3 of tau, MAP1B, or other known cytoskeletal protein substrates of GSK3, such as kinesin (Morfini et al., 2002) and collapsin response mediator protein-2 (Cole et al., 2007), could lead to abnormal microtubule dynamics and function that may contribute to abnormal neural plasticity in FXS.

Glycogen synthase kinase-3 is known to regulate by phosphorylation the activity of a relatively large number of transcription factors (Grimes and Jope, 2001a). Thus, altered transcription caused by aberrant transcription factor regulation by hyperactive GSK3 in FXS brain may exacerbate abnormal translation caused by loss of FMRP. Two representative examples that may be important in FXS are cyclic AMP response element binding protein (CREB) and Heat Shock Factor-1 (HSF-1). CREB regulates many critical processes, such as formation of long term memory and maintenance of synaptic plasticity (Alberini, 2009; Benito and Barco, 2010), both key processes that are impaired in FXS. CREB is active when phosphorylated on serine-133, and this phosphorylation creates a site for GSK3 to bind and phosphorylate serine-129, which inactivates CREB (Wang et al., 1994; Grimes and Jope, 2001b). Thus, hyperactive GSK3 in FXS brain may reduce the learning and neural plasticity functions of CREB by abnormally inactivating CREB. FMRP over-expression increases cyclic AMP production (Berry-Kravis and Ciurlionis, 1998), cyclic AMP production is defective in platelets from patients with FXS (Berry-Kravis and Sklena, 1993), induced levels of cyclic AMP are substantially reduced in platelets and in brains of Fmrl knockout mice and in human FXS neural cells (Kelley et al., 2007), and using the drosophila model of FXS, Dockendorff et al. (2002) reported that $d f m r 1$ is required for normal CREB activity. Thus, CREB activation may be impaired in FXS brain and further impaired by the inhibition induced by GSK3. The transcription factor HSF-1 is activated in response to many stressors because it is a crucial component of cellular mechanisms responding to abnormal or misfolded protein accumulation. Since FMRP is thought to suppress translation of many proteins, its deficiency in FXS may result in aberrantly expressed proteins. Activation of HSF-1 in response to abnormal protein accumulation is important because it controls the expression of heat shock proteins, such as hsp70, which chaperone proteins to prevent their accumulation and aggregation within cells. The action of HSF-1 may be impaired by hyperactive GSK3 in FXS brain because GSK3 phosphorylates HSF-1, resulting in its inactivation (Chu et al., 1996; Bijur and Jope, 2000; Xavier et al., 2000). Thus, these two transcription factors exemplify mechanisms by which hyperactive GSK3 in FXS brain may exacerbate mechanisms contributing to the impairments associated with FXS.

The amyloid precursor protein (APP) regulates synaptic function in neurons and also is proteolyzed to amyloid- $\beta$ peptides $(A \beta)$ that can be toxic, particularly in the realm of Alzheimer's disease. FMRP was found to repress APP translation (Westmark and Malter, 2007; Lee et al., 2010), and large increases in APP levels were found in cortical extracts from 14-day-old Fmrl knockout mice (Liao et al., 2008). Examination of the levels of soluble amyloid$\beta$ peptides demonstrated elevated levels in multiple strains of Fmr1 knockout mice (Westmark and Malter, 2007), which have been suggested to contribute to impairments associated with FXS (Malter et al., 2010). These findings may be associated with the detrimental actions of GSK3 in FXS because APP is phosphorylated by GSK3 (Aplin et al., 1996; Wen et al., 2008). Importantly, GSK3 has been reported to promote the processing of APP to amyloid- $\beta$ peptides (Phiel et al., 2003; Su et al., 2004). Since GSK3 inhibitors reduce the production of amyloid- $\beta$ peptides, this may contribute to their therapeutic effects if amyloid- $\beta$ peptides contribute to impairments in FXS.

Although investigations of neuronal characteristics greatly predominant in the field of FXS research, altered functions of other cell types due to FMRP deficiency undoubtedly contribute to FXS-associated phenotypes and may provide additional targets for therapeutic interventions for normalizing some characteristics of FXS. For example, GSK3 $\alpha$ was found to be hyperactivated in testis from FX mice, which display the macroorchidism evident in patients with FXS, and this was significantly reduced by only 4 weeks of lithium treatment to inhibit GSK3 (Yuskaitis et al., 2010b). Alterations in FMRP-deficient astrocytes may be particularly important, as indicated by the remarkable findings that incubation of primary hippocampal neurons from FX mice with wild-type astrocytes led to normalization of some abnormalities in the FX neurons, while FX astrocytes induced abnormalities in co-cultured wild-type neurons (Jacobs and Doering, 2010; Jacobs et al., 2010). FX mouse brains also exhibit elevated levels of GFAP, a marker of astrogliosis, and lithium treatment reduced GFAP levels (Yuskaitis et al., 2010b). GFAP expression is induced by activation of the transcription factor STAT3, and GSK3 promotes STAT3 activation (Beurel and Jope, 2008), raising the possibility that hyperactive GSK3 in FX mouse brain drives STAT3-mediated GFAP expression, which can be reduced by GSK3 inhibitors.

Thus, these examples represent only a few of the many potential mechanisms by which hyperactive GSK3 may contribute to the pathology of FXS. Identification of the abnormalities in FX mice that are corrected by administration of GSK3 inhibitors may clarify which of the targets of GSK3 is important in the phenotypes displayed by FX mice.

\section{SUMMARY}

Altogether, lithium has proven to be beneficial for a surprisingly large number of different phenotypes in FX mice and a pilot trial supported the possibility that this may translate into contributing to the treatment of patients with FXS. Improving upon lithium's actions in FXS likely will require clarifying to what extent they result from inhibition of GSK3. In FX mice, heightened susceptibility to audiogenic seizures is almost certainly controlled by inhibiting GSK3, since three structurally dissimilar GSK3 inhibitors normalized this susceptibility without affecting responses of wild-type mice. Evidence also suggests that locomotor hyperactivity can be reduced by targeting GSK3 based on the normalizing actions of the GSK3 inhibitor SB216763 as well as lithium. However, for the other identified therapeutic actions of lithium in FX mice, the information available is largely correlative: GSK3 is hyperactive in the brains of FX mice, lithium inhibits GSK3, and MPEP also inhibits GSK3 in FX brain regions. Thus, it remains to be established if other highly specific inhibitors of GSK3 will prove more beneficial than lithium in the treatment of FXS. If this is established, it would open the way for the application to FXS treatment of the many new selective inhibitors of GSK3 that 
have been developed in recent years. Since GSK3 influences many cellular processes, it is unlikely that complete inhibition of GSK3 should be an objective or would be tolerated. Rather, similar to the partial inhibition of GSK3 that is achieved by therapeutic levels of lithium in the treatment of bipolar disorder (Li and Jope, 2010), as well as in FX mice, dampening of the abnormally active GSK3

\section{REFERENCES}

Alberini, C. M. (2009). Transcription factors in long-term memory and synaptic plasticity. Physiol. Rev. 89, 121-145.

Antar, L. N., Afroz, R., Dictenberg, J. B., Carroll, R. C., and Bassell, G. J. (2004). Metabotropic glutamate receptor activation regulates fragile $\mathrm{x}$ mental retardation protein and FMR1 mRNA localization differentially in dendrites and at synapses. $J$. Neurosci. 11, 2648-2655.

Aplin, A. E., Gibb, G. M., Jacobsen, J. S., Gallo, J. M., and Anderton, B. H. (1996). In vitro phosphorylation of the cytoplasmic domain of the amyloid precursor protein by glycogen synthase kinase-3 $\beta$. J. Neurochem. 67, 699-707.

Bain, J., Plater, L., Elliott, M., Shpiro, N., Hastie, C. J., McLauchlan, H., Klevernic, I., Arthur, J. S., Alessi, D. R., and Cohen, P. (2007). The selectivity of protein kinase inhibitors: a further update. Biochem. J. 408, 297-315.

Bakker, C. E., Verheij, C., Willemsen, R., van der Helm, R., Oerlemans, F., Vermay, M., Bygrave, A., Hoogeveen, A., Oostra, B. A., Reyniers, E., De Boule, K., D’Hooge, R., Cras, R., van Velzen, D., Nagels, G., Martin, J. J., De Deyn, P. P., Darby, J. K., and Willems, P. J. (1994). Fmrl knockout mice: a model to study fragile $\mathrm{X}$ mental retardation. The Dutch-Belgian fragile X consortium. Cell 78, 23-33.

Bardoni, B., and Mandel, J. L. (2002). Advances in understanding of fragile $\mathrm{x}$ pathogenesis and FMRP $\mathrm{f}$ unction and in identification of $\mathrm{X}$ linked mental retardation genes. Curr. Opin. Genet. Dev. 12, 284-293.

Bardoni, B., Mandel, J. L., and Fisch, G. S. (2000). FMR1 gene and fragile X. Am. J. Med. Genet. 97, 153-163.

Bear, M. F., Huber, K. M., and Warren, S. T. (2004). The mGluR theory of fragile X mental retardation. Trends Neurosci. 27, 370-377.

Belmonte, M. K., and Bourgeron, T. (2006). Fragile X syndrome and autism at the intersection of genetic and neural networks. Nat. Neurosci. 9, 1221-1225.

Benito, E., and Barco, A. (2010). CREB's control of intrinsic and synaptic plasticity: implications for CREBdependent memory models. Trends Neurosci. 33, 230-240.
Bernerdet, M., and Crusio, W. E. (2006). Fmr1 KO mice as a possible model of autistic features. ScientificWorldJournal 6, 1164-1176.

Berry-Kravis, E., and Ciurlionis, R. (1998). Overexpression of fragile X gene (FMR-1) transcripts increases cAMP production in neural cells. $J$. Neurosci. Res. 51, 41-48.

Berry-Kravis, E., and Sklena, P. (1993). Demonstration of abnormal cyclic AMP production in platelets from patients with fragile $\mathrm{X}$ syndrome. Am. J. Med. Genet. 45, 81-87.

Berry-Kravis, E., Sumis, A., Hervey, C., Nelson, M., Porges, S. W., Weng, N., Weiler, I. J., and Greenough, W. T. (2008). Open-label treatment trial of lithium to target the underlying defect in fragile X syndrome. J. Dev. Behav. Pediatr. 29, 293-302.

Beurel, E., and Jope, R. S. (2008). Differential regulation of STAT family members by glycogen synthase kinase-3. J. Biol. Chem. 283, 21934-21944.

Bhat, R., Xue, Y., Berg, S., Hellberg, S., Ormö, M., Nilsson, Y., Radesäter, A. C., Jerning, E., Markgren, P. O., Borgegård, T., Nylöf, M., GiménezCassina, A., Hernández, F., Lucas, J. J., Díaz-Nido, J., and Avila, J. (2003). Structural insights and biological effects of glycogen synthase kinase 3-specific inhibitor AR-A014418. J. Biol. Chem. 278, 45937-45945.

Bijur, G. N., and Jope, R. S. (2000). Opposing actions of phosphatidylinositol 3-kinase and glycogen synthase kinase- $3 \beta$ in the regulation of HSF-1 activity. J. Neurochem. 75, 2401-2408.

Brown, M. R., Kronengold, J., Gazula, V. R., Chen, Y., Strumbos, J. G., Sigworth, F. J., Navaratnam, D., and Kaczmarek, L. K. (2010). Fragile X mental retardation protein controls gating of the sodium activated potassium channel Slack. Nat. Neurosci. 13, 819-821.

Brown, V., Small, K., Lakkis, L., Feng, Y., Gunter, C., Wilkinson, K. D., and Warren, S. T. (1998). Purified recombinant Fmrp exhibits selective RNA binding as an intrinsic property of the fragile $\mathrm{X}$ mental retardation protein. J. Biol. Chem. 273, 15521-15527.

Cho, J. H., and Johnson, G. V. W. (2004). Primed phosphorylation of

associated with FXS with new GSK3 inhibitors may be a reasonable therapeutic goal.

\section{ACKNOWLEDGMENTS}

Research in the authors' laboratory was funded by grants from the FRAXA Foundation and the NIMH (MH038752 and MH092970).

tau at Thr231 by glycogen synthase kinase $3 \beta(\mathrm{GSK} 3 \beta)$ plays a critical role in regulating tau's ability to bind and stabilize microtubules. $J$. Neurochem. 88, 349-358.

Choi, C. H., McBride, S. M., Schoenfeld, B. P., Liebelt, D. A., Ferreiro, D., Ferrick, N. J., Hinchey, P., Kollaros, M., Rudominer, R. L., Terlizzi, A. M., Koenigsberg, E., Wang, Y., Sumida, A., Nguyen, H. T., Bell, A. J., McDonald, T. V., and Jongens, T. A. (2009). Age-dependent cognitive impairment in a Drosophila Fragile X model and its pharmacological rescue. Biogerontology 11, 347-362.

Choi, C. H., Schoenfelda, B. P., Bella, A. J., Hincheya, P., Kollarosa, M., Gertnerd, M. J., Wooe, N. H., Tranfagliaf, M. R., Bear, M. F., Zukind, R. S., McDonald, T. V., Jongens, T. A., and McBride, S. M. (2011). Pharmacological reversal of synaptic plasticity deficits in the mouse model of fragile $\mathrm{X}$ syndrome by group II mGluR antagonist or lithium treatment. Brain Res. 1380, 106-119.

Chu, B., Soncin, F., Price, B. D., Stevenson, M. A., and Calderwood, S. K. (1996). Sequential phosphorylation by mitogen-activated protein kinase and glycogen synthase kinase 3 represses transcriptional activation by heat shock factor-1. J. Biol. Chem. 271, 30847-30857.

Coghlan, M. P., Culbert, A. A., Cross, D. A., Corcoran, S. L., Yates, J. W., Pearce, N. J., Rausch, O. L., Murphy, G. J., Carter, P. S., Roxbee Cox, L., Mills, D., Brown, M. J., Haigh, D., Ward, R. W., Smith, D. G., Murray, K. J., Reith, A. D., and Holder, J. C. (2000). Selective small molecule inhibitors of glycogen synthase kinase- 3 modulate glycogen metabolism and gene transcription. Chem. Biol. 7, 793-803.

Cole, A. R., Noble, W., van Aalten, L., Plattner, F., Meimaridou, R., Hogan, D., Taylor, M., LaFrancois, J., GunnMoore, F., Verkhratsky, A., Oddo, S., LaFerla, F., Giese, K. P., Dineley, K. T., Duff, K., Richardson, J. C., Yan, S. D., Hanger, D. P., Allan, S. M., and Sutherland, C. (2007). Collapsin response mediator protein-2 hyperphosphorylation is an early event in Alzheimer's disease progression. J. Neurochem. 103, 1132-1144.
Comery, T. A., Harris, J. B., Willems, P. J., Oostra, B. A., Irwin, S. A., Weiler, I. J., and Greenough, W. T. (1997). Abnormal dendritic spines in fragile $\mathrm{x}$ knockout mice: maturation and pruning deficits. Proc. Natl. Acad. Sci. U.S.A. 94, 5401-5404.

Crawford, D. C., Acuna, J. M., and Sherman, S. (2001). FMR1 and the fragile $\mathrm{x}$ syndrome: human genome epidemiology review. Genet. Med. 3, 359-371.

Dockendorff, T. C., Su, H. S., McBride, S. M., Yang, Z., Choi, C. H., Siwicki, K. K., Sehgal, A., and Jongens, T. A. (2002). Drosophila lacking dfmrl activity show defects in circadian output and fail to maintain courtship interest. Neuron 32, 973-984.

Dölen, G., Osterweil, E., Rao, B. S., Smith, G. B., Auerbach, B. D., Chattarji, S., and Bear, M. F. (2007). Correction of fragile $\mathrm{X}$ syndrome in mice. Neuron 56, 955-962.

Feng, Y., Zhang, F., Lokey, L. K., Chastain, J. L., Lakkis, L., Eberhart, D., and Warren, S. T. (1995). Translational suppression by trinucleotide repeat expansion at FMR1. Science 268, 731-734.

Garcia-Perez, J., Avila, J., and Diaz-Nido, J. (1998). Implication of cyclindependent kinases and glycogen synthase kinase 3 in the phosphorylation of microtubule-associated protein $1 \mathrm{~B}$ in developing neuronal cells. J. Neurosci. Res. 52, 445-452.

Grimes, C. A., and Jope, R. S. (2001a). The multi-faceted roles of glycogen synthase kinase- $3 \beta$ in cellular signaling. Prog. Neurobiol. 65, 391-426.

Grimes, C. A., and Jope, R. S. (2001b). CREB DNA binding activity is inhibited by glycogen synthase kinase- $3 \beta$ and facilitated by lithium. J. Neurochem. 78, 1219-1232.

Hagerman, R. J., Ono, M. Y., and Hagerman, P. J. (2005). Recent advances in fragile $\mathrm{X}$ : a model for autism and neurodegeneration. Curr. Opin. Psychiatry 18, 490-496.

Hatton, D. D., Sideris, J., Skinner, M., Mankowski, J., Bailey, D. B. Jr., Roberts, J., and Mirrett, P. (2006). Autistic behavior in children with fragile $\mathrm{X}$ syndrome: prevalence, stability, and the impact of FMRP. Am. J. Med. Genet. A 140A, 1804-1813. 
Hong, M., Chen, D. C., Klein, P. S., and Lee, V. M. (1997). Lithium reduces tau phosphorylation by inhibition of glycogen synthase kinase-3. J. Biol. Chem. 272, 25326-25332.

Huber, K. M., Gallagher, S. M., Warren, S. T., and Bear, M. F. (2002). Altered synaptic plasticity in a mouse model of fragile $\mathrm{X}$ mental retardation. Proc. Natl. Acad. Sci. U.S.A. 99, 7746-7750.

Irwin, S. A., Idupulapati, M., Gilbert, M. E., Harris, J. B., Chakravarti, A. B., Rogers, E. J., Crisostomo, R. A., Larsen, B. P., Mehta, A., Alcantara, C. J., Patel, B., Swain, R. A., Weiler, I. J., Oostra, B. A., and Greenough, W. T. (2002). Densdritic spine and dendritic field characteristics of layer $\mathrm{V}$ pyramidal neurons in the visual cortex of fragile-x knockout mice. Am. J. Med. Genet. 111, 140-146.

Irwin, S. A., Patel, B., Idupulapati, M., Harris, J. B., Crisostomo, R. A., Larsen, B. P., Kooy, F., Willems, P. J., Cras, P., Kozlowski, P. B., Swain, R. A., Weiler, I. J., and Greenough, W. T. (2001). Abnormal dendritic spine characteristics in the temporal and visual cortices of patients with fragile-X syndrome: a quantitative examination. Am. J. Med. Genet. 98, 161-167.

Jacobs, S., and Doering, L. C. (2010). Astrocytes prevent abnormal neuronal development in the fragile $\mathrm{x}$ mouse. J. Neurosci. 30, 4508-4514.

Jacobs, S., Nathwani, M., and Doering, L. C. (2010). Fragile X astrocytes induce developmental delays in dendrite maturation and synaptic protein expression. BMC Neurosci. 11, 132. doi:10.1186/1471-2202-11-132

Johnson, G. V. W., and Bailey, C. D. (2002). Tau, where are we now? J. Alzheimers Dis. 4, 375-398.

Jope, R. S. (1999). A bimodal model of the mechanism of action of lithium. Mol. Psychiatry 4, 21-25.

Jope, R. S. (2003). Lithium and GSK-3: one inhibitor, two inhibitory actions, multiple outcomes. Trends Pharmacol. Sci. 24, 441-443.

Jope, R. S., and Johnson, G. V. W. (2004). The glamour and gloom of glycogen synthase kinase-3. Trends Biochem. Sci. 29, 95-102.

Kelley, D. J., Davidson, R. J., Elliott, J. L., Lahvis, G. P., Yin, J. C., and Bhattacharyya, A. (2007). The cyclic AMP cascade is altered in the fragile $\mathrm{X}$ nervous system. PLoS ONE 2, e931 doi:10.1371/journal.pone.0000931

Klein, P. S., and Melton, D. A. (1996). A molecular mechanism for the effect of lithium on development. Proc. Natl. Acad. Sci. U.S.A. 93, 8455-8459.
Kooy, R. F., Willemsen, R., and Oostra, B. A. (2000). Fragile X syndrome at the turn of the century. Mol. Med. Today 6, 193-198.

Krueger, D. D., Osterweil, E. K., Chen, S. P., Tye, L. D., and Bear, M. F. (2011). Cognitive dysfunction and prefrontal synaptic abnormalities in a mouse model of fragile $\mathrm{X}$ syndrome. Proc. Natl. Acad. Sci. U.S.A. 108, 2587-2592.

Laggerbauer, B., Ostareck, D., Keidel, E. M., Ostareck-Lederer, A., and Fischer, U. (2001). Evidence that fragile $\mathrm{X}$ mental retardation protein is a negative regulator of translation. Hum. Mol. Genet. 10, 329-338.

Laurence, J. A., and Fatemi, S. H. (2005). Glial fibrillry acidic protein is elevated in superior frontal, parietal, and cerebellar cortices of autistic subjects. Cerebellum 4, 206-210.

Leclerc, S., Garnier, M., Hoessel, R., Marko, D., Bibb, J. A., Snyder, G. L., Greengard, P., Biernat, J., Wu, Y. Z., Mandelkow, E. M., Eisenbrand, $\mathrm{G}$, and Meijer, L. (2001). Indirubins inhibit glycogen synthase kinase- $3 \beta$ and CDK5/p25, two protein kinases involved in abnormal tau phosphorylation in Alzheimer's disease. A property common to most cyclindependent kinase inhibitors? J. Biol. Chem. 276, 251-260.

Lee, E. K., Kim, H. H., Kuwano, Y., Abdelmohsen, K., Srikantan, S., Subaran, S. S., Gleichmann, M., Mughal, M. R., Martindale, J. L., Yang, X., Worley, P. F., Mattson, M. P., and Gorospe, M. (2010). hnRNP C promotes APP translation by competing with FMRP for APP mRNA recruitment to P bodies. Nat. Struct. Mol. Biol. 17, 732-739.

Leost, M., Schultz, C., Link, A., Wu, Y. Z., Biernat, J., Mandelkow, E. M., Bibb, J. A., Snyder, G. L., Greengard, P., Zaharevitz, D. W., Gussio, R., Senderowicz, A. M., Sausville, E. A., Kunick, C., and Meijer, L. (2000). Paullones are potent inhibitors of glycogen synthase kinase- $3 \beta$ and cyclin-dependent kinase 5/p25. Eur. J. Biochem. 267, 5983-5994.

$\mathrm{Li}, \mathrm{X}$., and Jope, R. S. (2010). Is Glycogen synthase kinase- 3 a central modulator in mood regulation? Neuropsychopharmacology 35, 2143-2154.

Liao, L., Park, S. K., Xu, T., Vanderklish, P., and Yates, J. R. III. (2008). Quantitative proteomic analysis of primary neurons reveals diverse changes in synaptic protein content in fmrl knockout mice. Proc. Natl. Acad. Sci. U.S.A. 105, 15281-15286.

Liu, Z. H., Chaung, D. M., and Smith, C. B. (2011). Lithium ameliorates phenotypic deficits in a mouse model of fragile X syndrome. Int. J. Neuropsychopharmacol. 14, 618-630.

Liu, Z. H., and Smith, C. B. (2009). Dissociation of social and nonsocial anxiety in a mouse model of fragile X syndrome. Neurosci. Lett. 454, 62-66.

Lu, R., Wang, H., Liang, Z., Ku, L., O’Donnell, W. T., Li, W., Warren, S. T., and Feng, Y. (2004). The fragile $\mathrm{X}$ protein controls microtubuleassociated protein $1 \mathrm{~B}$ translation and microtubule stability in brain neuron development. Proc. Natl. Acad. Sci. U.S.A. 101, 15201-15206.

Lucas, F. R., Goold, R. G., GordonWeeks, P. R., and Salinas, P. C. (1998). Inhibition of GSK-3 $\beta$ leading to the loss of phosphorylated MAP-1B is an early event in axonal remodeling induced by WNT-7a or lithium. J. Cell Sci. 111, 1351-1361.

Maddalena, A., Richards, C. S., McGinniss, M. J., Brothman, A., Desnick R. J., Grier, R. E., Hirsch, B., Jacky, P., McDowell, G. A., Popovich, B. Watson, M., and Wolff, D. J. (2001) Technical standards and guidelines for fragile $\mathrm{X}$ : the first of a series of disease-specific supplements to the Standards and Guidelines for Clinical Genetics Laboratories of the American College of Medical Genetics. Quality Assurance Subcommittee of the Laboratory Practice Committee. Genet. Med. 3, 200-205.

Malter, J. S., Ray, B. C., Westmark, P. R., and Westmark, C. J. (2010). Fragile X syndrome and Alzheimer's disease: another story about APP and beta-amyloid. Curr. Alzheimer Res. 7, 200-206.

Martinez, A., Alonso, M., Castro, A. Pérez, C., and Moreno, F. J. (2002). First non-ATP competitive glycogen synthase kinase $3 \beta$ (GSK$3 \beta)$ inhibitors: thiadiazolidinones (TDZD) as potential drugs for the treatment of Alzheimer's disease. $J$. Med. Chem. 45, 1292-1299.

Martinez, A., Castro, A., Medina, M. (eds). (2006). Glycogen Synthase Kinase 3 (GSK-3) and its Inhibitors. John Wiley and Sons, Inc.

Martinez, A., Gil, C., and Perez, D. I. (2011). Glycogen synthase kinase 3 inhibitors in the next horizon for Alzheimer's disease treatment. Int. J. Alzheimers Dis. 2011, 280502.

McBride, S. M., Choi, C. H., Wang, Y., Liebelt, D., Braunstein, E., Ferreiro, D., Sehgal, A., Siwicki, K. K., Dockendorff, T. C., Nguyen, H. T. McDonald, T. V., and Jongens, T. A. (2005). Pharmacological rescue of synaptic plasticity, courtship behavior, and mushroom body defects in a Drosophila model of fragile $\mathrm{X}$ syndrome. Neuron 45, 753-764.

McManus, E. J., Sakamoto, K., Armit, L. J., Ronaldson, L., Shpiro, N., Marquez, R., and Alessi, D. R. (2005). Role that phosphorylation of GSK3 plays in insulin and Wnt signaling defined by knockin analysis. $E M B O$ J. 24, 1571-1583.

McNaughton, C. H., Moon, J., Strawderman, M. S., Maclean, K. N., Evans, J., and Strupp, B. J. (2008). Evidence for social anxiety and impaired social cognition in a mouse model of fragile X syndrome. Behav. Neurosci. 122 293-300.

Min, W. M., Yuskaitis, C. J., Yan, Q. J., Sikorski, C., Chen, S., Jope, R. S. and Bauchwitz, R. P. (2009). Elevated glycogen synthase kinas-3 activity in fragile $\mathrm{x}$ mice: key metabolic regulator with evidence for treatment potential. Neuropharmacology 56, 463-472.

Mines, M. A., Beurel, E., and Jope, R. S. (2011). Regulation of cell survival mechanisms in Alzheimer's disease by glycogen synthase kinase-3. Int. J. Alzheimers Dis. 2011, 861072

Mines, M. A., Yuskaitis, C. J., King, M. K., Beurel, E., and Jope, R. S. (2010). GSK3 influences social preference and anxiety-related behaviors during social interaction in a mouse model of fragile $\mathrm{X}$ syndrome and autism. PLoS ONE 5, e9706. doi:10.1371/journal.pone.0009706

Mineur, Y. S., Huynh, L. X., and Crusio, W. E. (2006). Social behavior deficits in the Fmrl mutant mouse. Behav. Brain Res. 168, 172-175.

Mineur, Y. S., Sluyter, F., de Wit, S., Oostra, B. A., and Crusio, W. E. (2002). Behavioral and neuroanatomical characterization of the Fmrl knockout mouse. Hippocampus 12, 39-46.

Morfini, G., Szebenyi, G., Elluru, R., Ratner, N., and Brady, S. T. (2002). Glycogen synthase kinase 3 phosphorylates kinesin light chains and negatively regulates kinesin-based motility. EMBO J. 21, 281-293.

Moy, S. S., Nadler, J. J., Young, N. B., Nonneman, R. J., Grossman, A. W., Murphy, D. L., D'Ercole, A. J., Crawley, J. N., Magnuson, T. R., and Lauder, J. M. (2009). Social approach in genetically engineered mouse lines relevant to autism. Genes Brain Behav. 8 , 129-142.

Musumeci, S. A., Bosco, P., Calabrese, G., Bakker, C., De Sarro, G. B., Elia, M., Ferri, R., and Oostra, B. A. (2000). Audiogenic seizures susceptibility in transgenic mice with fragile $\mathrm{X}$ syndrome. Epilepsia 41, 19-23. 
Peineau, S., Taghibiglou, C., Bradley, C., Wong, T. P., Liu, L., Lu, J., Lo, E., Wu, D., Saule, E., Bouschet, T., Matthews, P., Issac, J. T., Bortolotto, Z. A., Wang, Y. T., and Collingridge, G. L. (2007). LTP Inhibits LTD in the Hippocampus via regulation of GSK3ß. Neuron 53, 703-717.

Phiel, C. J., Wilson, C. A., Lee, V. M., and Klein, P. S. (2003). GSK-3 $\beta$ regulates production of Alzheimer's disease amyloid-beta peptides. Nature 423, 435-439

Pieretti, M., Zhang, F. P., Fu, Y. H., Warren, S. T., Oostra, B. A., Caskey, C. T., and Nelson, D. L. (1991). Absence of expression of FMR-1 gene in fragile $\mathrm{x}$ syndrome. Cell 66, 817-822.

Plotkin, B., Kaidanovich, O., Talior, I., and Eldar-Finkelman, H. (2003). Insulin mimetic action of synthetic phosphorylated peptide inhibitors of glycogen synthase kinase-3. J. Pharmacol. Exp. Ther. 305, 974-980.

Spencer, C. M., Alekseyenko, O., Serysheva, E., Yuva-Paylor, L. A., and Paylor, R. (2005). Altered anxietyrelated and social behaviors in the Fmrl knockout mouse model of fragile X syndrome. Genes Brain Behav. 4, 420-430.

Stambolic, V., Ruel, L., and Woodgett, J. R. (1996). Lithium inhibits glycogen synthase kinase- 3 activity and mimics wingless signalling in intact cells. Curr. Biol. 6, 1664-1668.

Su, Y., Ryder, J., Li, B., Wu, X., Fox, N., Solenberg, P., Brune, K., Paul, S., Zhou, Y., Liu, F., and Ni, B. (2004). Lithium, a common drug for bipolar disorder treatment, regulates amyloid-beta precursor protein processing. Biochemistry 43, 6899-6908.

Vargas, D. L., Nascimbene, C., Krishnan, C., Zimmerman, A. W., and Pardo, C. A. (2005). Neuroglial activation and neuroinflammation in the brains of patients with autism. Ann. Neurol. $57,67-81$.

Wagman, A. S., Johnson, K. W., and Bussiere, D. E. (2004). Discovery and development of GSK3 inhibitors for the treatment of type 2 diabetes. Curr. Pharm. Des. 10, 1105-1137.

Wan, L., Dockendorff, T. C., Jongens, T. A., and Dreyfuss, G. (2000). Characterization of dFMR1, a Drosophila melanogaster homolog of the fragile $\mathrm{X}$ mental retardation protein. Mol. Cell. Biol. 20, 8536-8547.

Wang, Q. M., Roach, P. J., and Fiol, C. J. (1994). Use of a synthetic peptide as a selective substrate for glycogen synthase kinase 3. Anal. Biochem. 220, 397-402.

Weiler, I. J., and Greenough, W. T. (1999). Synaptic synthesis of the fragile X protein: possible involvement in synapse maturation and elimination. Am. J. Med. Genet. 83, 248-252.

Weiler, I. J., Irwin, S. A., Klintsova, A. Y., Spencer, C. M., Brazelton, A. D., Miyashiro, K., Comery, T. A., Patel, B., Eberwine, J., and Greenough, W. T. (1997). Fragile X mental retardation protein is translated near synapses in response to neurotransmitter activation. Proc. Natl. Acad. Sci. U.S.A. 10, 5395-5400.

Wen, Y., Planel, E., Herman, M., Figueroa, H. Y., Wang, L., Liu, L.,
Lau, L. F., Yu, W. H., and Duff, K. E. (2008). Interplay between cyclindependent kinase 5 and glycogen synthase kinase $3 \beta$ mediated by neuregulin signaling leads to differential effects on tau phosphorylation and amyloid precursor protein processing. J. Neurosci. 28, 2624-2632.

Westmark, C. J., and Malter, J. S. (2007). FMRP mediates mGluR5dependent translation of amyloid precursor protein. PLoS Biol. 5, e52. doi:10.1371/journal.pbio.0050052

Woodgett, J. R. (1990). Molecular cloning and expression of glycogen synthase kinase-3/factor A. EMBO J. 9, 2431-2438.

Xavier, I. J., Mercier, P. A., McLoughlin, C. L., Ali, A., Woodgett, J. R., and Ovsenek, N. (2000). Glycogen synthase kinase $3 \beta$ negatively regulates both DNA-binding and transcriptional activities of heat shock factor 1. J. Biol. Chem. 275, 29147-29152.

Yan, Q. J., Asafo-Adjei, P. K., Arnold, H. M., Brown, R. E., and Bauchwitz, R. P. (2004). A phenotypic and molecular characterization of the fmr1tm1Cgr fragile X mouse. Genes Brain Behav. 3, 337-359.

Yan, Q. J., Rammal, M., Tranfaglia, M., and Bauchwitz, R. P. (2005). Suppression of two major fragile $\mathrm{X}$ syndrome mouse model phenotypes by the mGluR5 antagonist MPEP. Neuropharmacology 49, 1053-1066.

Yuskaitis, C. J., Mines, M. A., King, M. K., Sweatt, J. D., Miller, C. A., and Jope, R. S. (2010a). Lithium ameliorate altered glycogen synthase kinase- 3 and behavior on a mouse model of fragile $\mathrm{X}$ syndrome. Biochem. Pharmacol. 79, 632-646.

Yuskaitis, C. J., Beurel, E., and Jope, R. S. (2010b). Evidence of reactive astrocytes but not peripheral immune system activation in a mouse model of fragile X syndrome. Biochim. Biophys. Acta 1802, 1006-1012.

Zhang, Y. Q., Bailey, A. M., Matthies, H. J., Renden, R. B., Smith, M A., Speese, S. D., Rubin, G. M., and Broadie, K. (2001). Drosophila fragile X-related gene regulates the MAP1B homolog Futsch to control synaptic structure and function. Cell 107,591-603.

Conflict of Interest Statement: The authors declare that the research was conducted in the absence of any commercial or financial relationships that could be construed as a potential conflict of interest.

Received: 19 June 2011; accepted: 08 October 2011; published online: 01 November 2011.

Citation: Mines MA and Jope RS (2011) Glycogen synthase kinase-3: a promising therapeutic target for fragile $X$ syndrome. Front. Mol. Neurosci. 4:35. doi: 10.3389/fnmol.2011.00035

Copyright $\odot 2011$ Mines and Jope. Thi is an open-access article subject to a nonexclusive license between the authors and Frontiers Media SA, which permits use, distribution and reproduction in other forums, provided the original authors and source are credited and other Frontiers conditions are complied with. 